\title{
Bacteriopheophytin $a$ in the Active Branch of the Reaction Center of Rhodobacter sphaeroides Is Not Disturbed by the Protein Matrix as Shown by ${ }^{13} \mathrm{C}$ Photo-CIDNP MAS NMR
}

\author{
Karthick Babu Sai Sankar Gupta, ${ }^{\dagger}$ A. Alia, ${ }^{\dagger,}$ Francesco Buda, ${ }^{\dagger}$ Huub J. M. de Groot, ${ }^{\dagger}$ \\ and Jörg Matysik*,†, \\ ${ }^{\dagger}$ Institute of Chemistry, Leiden University, P.O. Box 9502, 2300 RA Leiden, The Netherlands \\ ${ }^{\ddagger}$ Institut für Analytische Chemie, Universität Leipzig, Linnéstr. 3, 04103 Leipzig, Germany
}

ABSTRACT: The electronic structure of bacteriopheophytin $a$ (BPhe $a$ ), the primary electron acceptor $\left(\Phi_{\mathrm{A}}\right)$ in photosynthetic reaction centers (RCs) of the purple bacterium Rhodobacter sphaeroides, is investigated by photochemically induced dynamic nuclear polarization (photo-CIDNP) magicangle spinning (MAS) NMR spectroscopy at atomic resolution. By using various isotope labeling systems, introduced by adding different ${ }^{13} \mathrm{C}$ selectively labeled $\delta$-aminolevulinic acid precursors in the growing medium of $R$. sphaeroides wild type

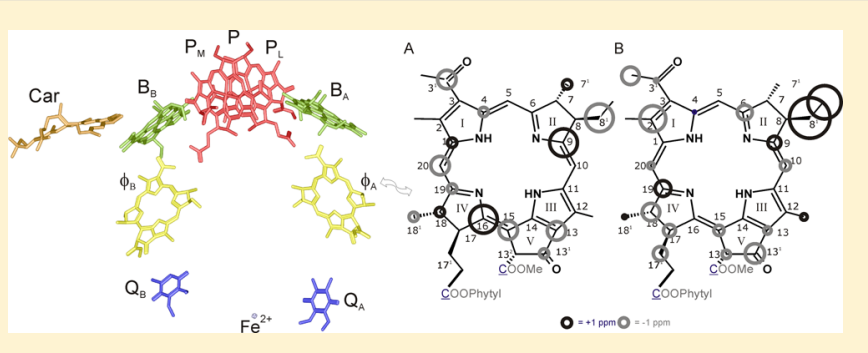
(WT), we were able to extract light-induced ${ }^{13} \mathrm{C}$ NMR signals originating from the primary electron acceptor. The assignments are backed by theoretical calculations. By comparison of these chemical shifts to those obtained from monomeric BPhe $a$ in solution, it is demonstrated that $\Phi_{\mathrm{A}}$ in the active branch appears to be electronically close to free bacteriopheophytin. Hence, there is little effect of the protein surrounding on the cofactor functionally which contributes with its standard redox potential to the electron transfer process that is asymmetric.

\section{INTRODUCTION}

Natural photosynthesis achieves the conversion of solar energy with a remarkably small set of cofactors, and the functional programming of the pigment chromophores is to a large extent encoded by their conformation, local environment, dynamics, and mutual interactions in the ground state. ${ }^{1-6}$ The photosynthetic apparatus of plants, algae, and bacteria contain densely packed pigment-pigment and pigment-protein complexes for harvesting light and separating electrons and protons across the photosynthetic membrane. ${ }^{7}$ Both the photosynthetic reaction centers (RCs) and the light harvesting antennae of the purple bacterium Rhodobacter sphaeroides contain networks of interacting cofactors. In the RC, four BChl $a$ and two bacteriopheophytin (BPhe) $a$ are positioned in an apparent symmetric arrangement and use the energy absorbed by the BChls in LH2 and LH1 light harvesting antennae complexes. Two BChl $a$ are bound to the $\mathrm{L}$ and $\mathrm{M}$ subunits of the protein complex and form an interacting dimer called the "Special Pair" (P) (Figure 1). On either side of the special pair an additional $\mathrm{BChl} a$ molecule is located, the accessory BChls $\left(\mathrm{B}_{\mathrm{A}}\right.$ and $\left.\mathrm{B}_{\mathrm{B}}\right)$. In addition, two BPhe $(\Phi)$ are positioned at an edge-to-edge distance of $\sim 14 \AA$ from the special pair. $^{8-10}$

Despite an approximate global symmetry in the arrangement of these six cofactors, their functioning is asymmetric, since charge separation proceeds exclusively over the A-branch, from the $\mathrm{P}$ to the $\Phi_{\mathrm{A}}$ in a complex quantum-classical coherent process involving a $\mathrm{P}^{+} \mathrm{B}_{\mathrm{A}}^{-}$intermediate, and interactions with amino acid side chains and protein-bound water. ${ }^{11-13}$ This electron transfer (ET) process has been well studied by various spectroscopic methods. EPR, ENDOR and optical techniques have provided insight into the electronic and spatial structure of the intermediates formed by $\mathrm{P}$ and $\Phi_{\mathrm{A}}$ during the ET reaction, and the role of the accessory BChls in the photochemistry has been clarified as well. ${ }^{12,14-20}$ In chlorophyll-protein complexes, packing effects produce both structural deformation and concomitant rearrangements of the electron density over the $\mathrm{BChl}$ macrocycles in their ground state. ${ }^{21}$

The discovery of the solid-state photo-CIDNP (photochemically induced dynamic nuclear polarization) effect for $R$. sphaeroides R26 RCs by continuous illumination with white light $^{22}$ offers NMR access to the electronic and spatial structure of both the donor and the acceptor in the primary charge separation process. By induction of a non-Boltzmann nuclear spin polarization upon photoreaction in rigid samples, ${ }^{23,24}$ a signal enhancement by a factor of more than 80000 has been observed by ${ }^{13} \mathrm{C}$ MAS NMR in several RCs. ${ }^{25-28}$ The effect has been observed for various photosynthetic RCs from bacteria, algae and plants $25,27,29-35$ as well as for a blue-light photoreceptor. ${ }^{36}$ Photo-CIDNP MAS NMR, in particular in combination with isotope labeling ${ }^{37,38}$ allows us to resolve with high selectivity the spatial and electronic structure at atomic resolution of both the donor and the acceptor molecules of the $P \Phi_{A}$

Received: December 10, 2012

Revised: March 1, 2013

Published: March 1, 2013 


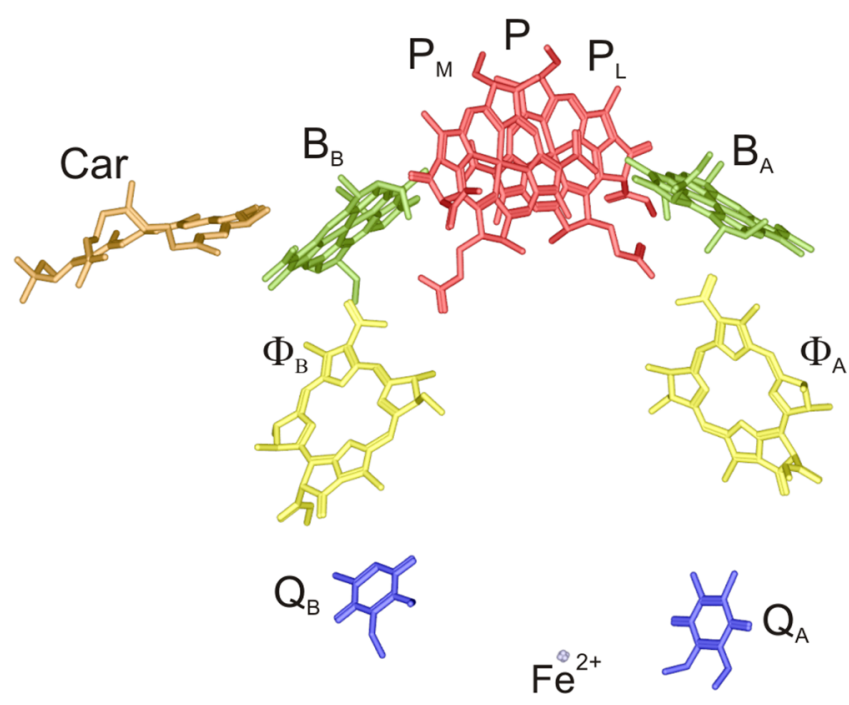

Figure 1. Arrangement of cofactors in reaction centers (RCs) of R. sphaeroides wildtype (WT). The primary electron donor, the special pair, is formed by the two bacteriochlorophyll $a(\mathrm{BChl})$ molecules, $\mathrm{P}_{\mathrm{M}}$ and $\mathrm{P}_{\mathrm{L}} . \mathrm{B}_{\mathrm{A}}$ and $\mathrm{B}_{\mathrm{B}}$ are accessory $\mathrm{BChl}$ cofactors, and $\Phi_{\mathrm{A}}$ and $\Phi_{\mathrm{B}}$ are bacteriopheophytin (BPhe) cofactors. On the acceptor side, two ubiquinone-10 cofactors $Q_{A}$ and $Q_{B}$ are localized, with a nonheme iron in between. Side chains are omitted for clarity. The symmetry of the cofactor arrangement is broken by a carotenoid cofactor Car. The light-induced electron transfer occurs selectively via branch A. [PDB entry $1 \mathrm{M} 3 \mathrm{X}$. The figure has been made with Accelrys Discovery Studio].

reactant ground state by cycling of the $\mathrm{RC}$ through its primary radical pair $\mathrm{P}^{+} \Phi_{\mathrm{A}}^{-}$state with light.

Recently, MAS NMR in the dark and with photo-CIDNP enhancement has provided a detailed view, with atomic selectivity, of $\mathrm{P}$ in its ground state. The analysis of ${ }^{13} \mathrm{C}$ shifts for the carbons in the aromatic ring has revealed packing effects on the two $\mathrm{BChl} a$ cofactors of $\mathrm{P}$, induced by the folding and self-assembly of the RC complex. ${ }^{1,2}$ There is converging evidence that the packing leads to electronic asymmetry of the form $\mathrm{P}_{\mathrm{L}}^{\delta-} \mathrm{P}_{\mathrm{M}}^{\varepsilon-}$ between the two $\mathrm{BChl} a$ of the $\mathrm{P}$, due to variation of local side chain interactions, protein-induced macrocycle distortion, and an asymmetric electronic environment. ${ }^{1,38-41}$ In addition to this time-averaged asymmetric electronic offset, a coupling with two collective low-frequency vibrational modes is thought to lead to dynamics of the asymmetry with timedependent localization of the highest occupied orbital and variation of the orbital energy levels. ${ }^{4}$

Although MAS NMR and photo-CIDNP have revealed the characteristic electronic and spatial structure on the $\mathrm{P}$ side of the $P \Phi_{\mathrm{A}}$ reactant state and have provided insight into the reaction coordinate connecting the reactant to the $\mathrm{P}^{+} \Phi_{\mathrm{A}}^{-}$ primary product state by providing experimental constraints to TDDFT modeling studies, the specific characteristics of the BPhe $a$ on the acceptor side were not yet resolved. The rate of formation of the $\mathrm{P}^{+} \Phi_{\mathrm{A}}^{-}$product depends strongly on the acceptor energy level relative to the $\mathrm{P}^{+} \mathrm{B}_{\mathrm{A}}^{-}$intermediate. For instance, when BPhe $a$ is replaced by plant pheophytin $a$ with a more negative redox potential, the free energy level of $\mathrm{P}^{+} \Phi_{\mathrm{A}}^{-}$is $\sim 200 \mathrm{~cm}^{-1}$ above $\mathrm{P}^{+} \mathrm{B}_{\mathrm{A}}^{-}$, and this slows down the forward electron transfer considerably. ${ }^{19,42}$

The specific aim of this study is to address the question of whether and how the BPhe $a$ of the active branch is tuned by the surrounding matrix in relation to the ET kinetics.
To achieve this, the selectivity and sensitivity of photo-CIDNP MAS NMR and of isotope labeling is combined. The lightenhanced NMR response of ${ }^{13} \mathrm{C}$ nuclei in the macrocycle that supports the frontier $\pi$-orbital system involved in the photochemistry is analyzed to explore the influence of the protein environment on the $\Phi_{\mathrm{A}}$ acceptor electronic ground state.

\section{MATERIALS AND METHODS}

Sample Preparation and Specific Isotopic Labeling. The isotope labeling of cofactors in RCs is achieved by using labeled $\delta$-aminolevulinic acid (ALA) that acts as a precursor for the biosynthesis of $\mathrm{BChl}$ and $\mathrm{BPhe}{ }^{43,44} \mathrm{By}$ enriching the growth medium with either $\left(3-{ }^{13} C_{1}\right),\left(4-{ }^{13} C_{1}\right),\left(5-{ }^{13} C_{1}\right)$, or $\left(\mathrm{u}-{ }^{13} \mathrm{C}_{5}\right)$-ALA labeled substrate, RCs that are labeled in the macroaromatic cycles of the cofactors are produced (Figure 2). ${ }^{2,38}$ The RCs were isolated as described previously. ${ }^{45}$ Quinones were removed by incubating the RCs at a concentration of $0.6 \mu \mathrm{M}$ in $4 \% \mathrm{LDAO}, 10 \mathrm{mM}$ o-phenanthroline, $10 \mathrm{mM}$ Tris buffer, $\mathrm{pH}$ 8.0, containing $0.025 \% \mathrm{LDAO}$ and $1 \mathrm{mM} \mathrm{EDTA}{ }^{46}$ Approximately $15 \mathrm{mg}$ of RC protein complex embedded in LDAO micelles was used for NMR experiments.

MAS NMR Experiments. NMR experiments were performed with a DMX-200 NMR spectrometer equipped with a double resonance MAS probe (Bruker, Karlsruhe, Germany). The sample was loaded into a clear 4-mm sapphire rotor, inserted into the MAS probe and frozen slowly at a low spinning frequency of $600 \mathrm{~Hz}$ to ensure a homogeneous sample distribution against the rotor wall. ${ }^{47}$ The light and dark spectra were collected with a Hahn echo pulse sequence with the CYCLOPS phase cycle of the $(\pi / 2)$ pulse and detection with proton decoupling using the TPPM sequence ${ }^{48}$ at a temperature of $223 \mathrm{~K}^{44}$ The optimum length of the $(\pi / 2)$ carbon pulse, determined on uniformly ${ }^{13} \mathrm{C}$ labeled tyrosine, was $\sim 4 \mu$ s and a recycle delay of $4 \mathrm{~s}$ was used. The sample was spinning with a MAS frequency of $8 \mathrm{kHz}$. A total number of 6240 scans were collected in approximately $7 \mathrm{~h}$ for u-ALA RCs, while for 3-ALA, 4-ALA and 5-ALA labeled bacterial RCs around 256 scans were collected in approximately $20 \mathrm{~min}$. An artificial line broadening of $30 \mathrm{~Hz}$ was applied prior to Fourier transformation. The ${ }^{13} \mathrm{C}$-MAS NMR spectra were referenced to the carbonyl resonance of solid tyrosine $\mathrm{HCl}$ at $172.1 \mathrm{ppm}$. A zero-order phase correction was applied to the dark and photo-CIDNP spectra of the RCs to correct the line shape asymmetry.

Theoretical Models and Methods. The coordinates for the initial model of the bacteriopheophytin molecule have been extracted from the 1M3X crystal structure of $R$. sphaeroides WT. ${ }^{10}$ From this crystal structure, the bacteriopheophytin $a$ of the active branch with residue id number of 855 has been used. This model was partially optimized by relaxing carbons and nitrogens in the porphyrin ring, and all the hydrogen atoms, while fixing the positions of the peripheral carbon atoms. In this way X-ray crystallography and molecular modeling refinement artifacts were corrected by DFT, while preserving the supramolecular structure of the system due to the applied constraints. A DFT model of a fully relaxed BPhe $a$ was obtained to mimic the free monomer in solution. Both geometry optimizations have been carried out in vacuum within the DFT framework with the ADF program ${ }^{49-51}$ using the Becke's ${ }^{52}$ and LeeYoung-Parr's ${ }^{53}$ gradient-corrected functional (BLYP) in conjunction with a TZP Slater-type basis set.

NMR chemical shifts have been computed with the ADF program. ${ }^{51}$ The calculated ${ }^{13} \mathrm{C}$ chemical shifts were referred 
A

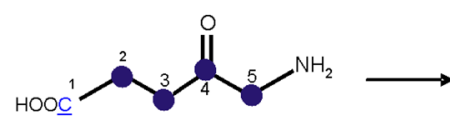

$\mathrm{u}-{ }^{13} \mathrm{C}_{5}-\delta$-Aminolevulinic acid

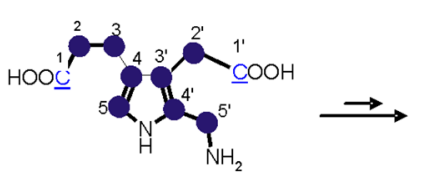

Porphobilinogen

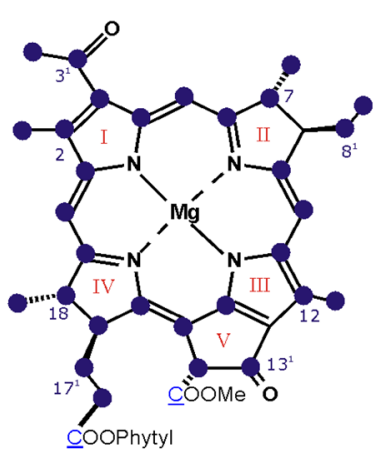

u-ALA-labeled bacteriochlorophyll

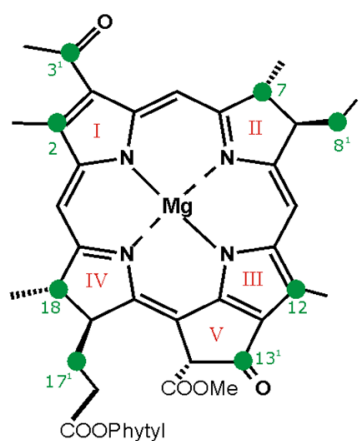

3-ALA-labeled bacteriochlorophyll

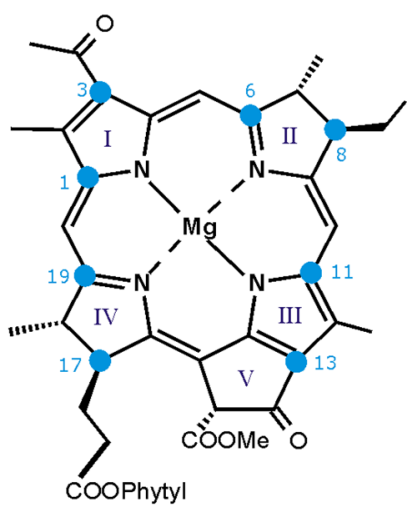

4-ALA-labeled bacteriochlorophyll

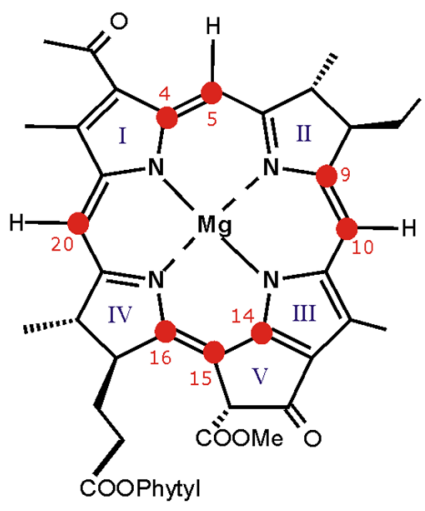

5-ALA-labeled bacteriochlorophyll

Figure 2. Biosynthetic pathways for the formation of uniformely and selectively ${ }^{13} \mathrm{C}$ isotope labeled bacteriocholorophyll $a$ (BChl) by feeding the bacteria with (A) $\mathrm{u}^{13} \mathrm{C}_{5}^{-}$, (B) $3-{ }^{13} \mathrm{C}_{1^{-}}$, (C) $4-{ }^{13} \mathrm{C}_{1^{-}}$, and (D) $5-{ }^{13} \mathrm{C}_{1}-\delta$-aminolevulinic acid.

to calculations performed on TMS and calibrated accordingly. The differences in the chemical shifts between the constrained and fully relaxed geometries of the BPhe $a$ has been obtained and compared with the experimental observations.

\section{RESULTS AND DISCUSSION}

Signal Intensity Enhancement in the u-ALA Labeled Sample. Figure 3 shows ${ }^{13} \mathrm{C}$ MAS NMR spectra of RCs of 
A

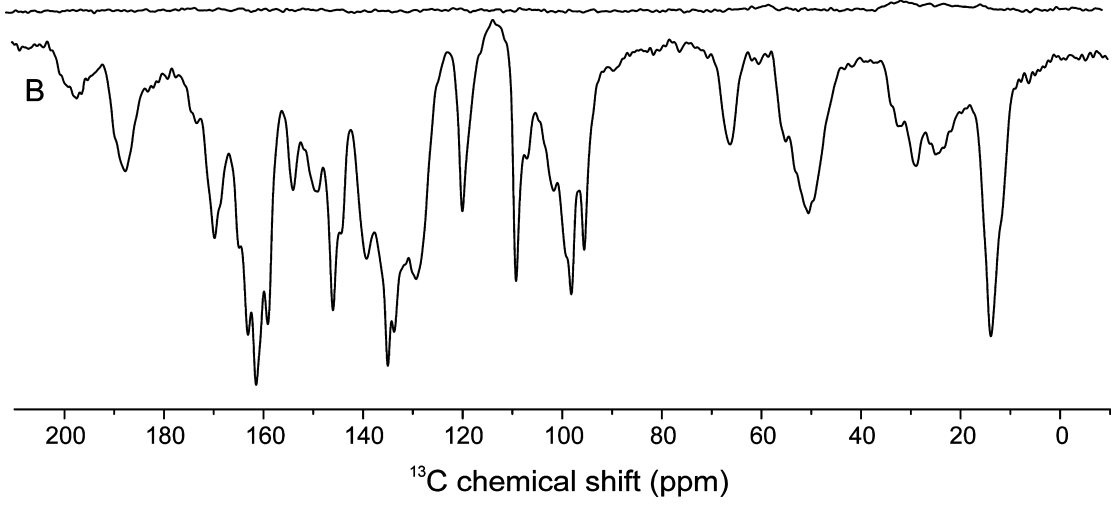

Figure 3. One-dimensional ${ }^{13} \mathrm{C}$ photo-CIDNP MAS NMR spectra of u-ALA labeled RCs of R. sphaeroides WT obtained (A) in the dark and (B) with continuous illumination using white light. All spectra have been collected in a magnetic field of $4.7 \mathrm{~T}$ at a temperature of $223 \mathrm{~K}$ with a spinning frequency of $8 \mathrm{kHz}$.

R. sphaeroides WT containing uniformly ${ }^{13} \mathrm{C}$ labeled $\mathrm{BChl}$ and BPhe cofactors. Trace A shows the data for the sample when it is measured in the dark. The signal is very weak and comprises a broad response around $35 \mathrm{ppm}$ from the aliphatic carbons in the protein. Upon illumination with continuous white light, strong signals appear (Figure 3, trace B). All light induced signals are emissive and are negative relative to the absorptive spectrum. The light-induced signals appear in spectral regions in which carbons of $\mathrm{BChl}$ and $\mathrm{BPhe}$ cofactors are resonating. This contrasts with data collected from RCs with ${ }^{13} \mathrm{C}$ at natural abundance, ${ }^{26}$ where only the response from the aromatic ${ }^{13} \mathrm{C}$ is enhanced. Obviously, the polarization is spread by spin diffusion within the frozen sample and allows also for enhancement of aliphatic carbons.

The overall signal intensity achieved here in samples with cofactors that are uniformly labeled in the macrocycle is significantly smaller than for samples with cofactors containing ${ }^{13} \mathrm{C}$ in natural abundance or samples with sparsely labeled cofactors. $^{37,38,54}$ The width of the peaks is due to the uniform labeling patterns caused by the huge dipolar couplings, which is $\sim 4.5 \mathrm{kHz}$ for ${ }^{13} \mathrm{C}-{ }^{13} \mathrm{C}$ pairs of a distance of $1.5 \AA{ }^{55-57}$ Timeresolved experiments using laser excitation immediately before the NMR acquisition reveal that the effect of the labeling on the ${ }^{13} \mathrm{C} \mathrm{T}_{1}$ by additional channels for spin diffusion and spin-spin relaxation is minimal (data not shown). Hence, the addition of nuclear spins affects the coherent spin dynamics in the build-up of nuclear polarization. In a future study, the additional complexity introduced by multiple labeling will be addressed further.

Peak Assignments. By using different labeling patterns and by exploiting the additional selectivity offered by the photoCIDNP mechanism it is possible to address the ground state NMR response with atomic selectivity for the ${ }^{13} \mathrm{C}$ carbons of the rings and the pheripheral side chains of the cofactors involved in the formation of the primary radical pair $\mathrm{P}^{+} \Phi_{\mathrm{A}}^{-}$. Selectively isotope labeled $3-{ }^{13} \mathrm{C}_{1}$-ALA, $4-{ }^{13} \mathrm{C}_{1}$-ALA, or $5-{ }^{13} \mathrm{C}_{1}$ ALA have been studied already and provided almost complete chemical shift assignments for signals originating from the donor $\mathrm{BChls} \mathrm{P}_{\mathrm{L}}$ and $\mathrm{P}_{\mathrm{M}}$, including the peripheral carbons. ${ }^{2,25,26,37,38,58}$ Here we aim to separate the responses from the $\Phi_{\mathrm{A}}$ from the strong background of the photo-CIDNP signals originating from the Special Pair. The chemical shift of the light-induced signals are listed in Table 1 and assigned to
Table 1. Complete Peak List of NMR ${ }^{13} \mathrm{C}$ Chemical Shifts with Index Numbers from the u-ALA RCs Spectrum ${ }^{a}$

\begin{tabular}{|c|c|c|c|}
\hline index & ${ }^{13} \mathrm{C}$ chemical shift (ppm) & index & ${ }^{13} \mathrm{C}$ chemical shift (ppm) \\
\hline 1 & (197.0) & 40 & 126.9 \\
\hline 2 & 195.6 & 41 & 119.5 \\
\hline 3 & 193.5 & 42 & 108.7 \\
\hline 4 & 189.4 & 43 & (107.5) \\
\hline 5 & $(188.6)$ & 44 & 106.6 \\
\hline 6 & 187.5 & 45 & 104.1 \\
\hline 7 & $(174.2)$ & 46 & 103.0 \\
\hline 8 & $(172.9)$ & 47 & 102.0 \\
\hline 9 & $(170.7)$ & 48 & 101.2 \\
\hline 10 & (169.3) & 49 & 100.4 \\
\hline 11 & $(168.2)$ & 50 & $(99.6)$ \\
\hline 12 & 166.5 & 51 & 98.3 \\
\hline 13 & 165.9 & 52 & $(97.6)$ \\
\hline 14 & 164.4 & 53 & $(95.1)$ \\
\hline 15 & 162.6 & 54 & $(65.8)$ \\
\hline 16 & 161.0 & 55 & $(55.6)$ \\
\hline 17 & 160.1 & 56 & 54.7 \\
\hline 18 & 158.5 & 57 & 52.7 \\
\hline 19 & 157.2 & 58 & $(52.5)$ \\
\hline 20 & (154.4) & 59 & 51.7 \\
\hline 21 & 153.6 & 60 & 50.9 \\
\hline 22 & 151.5 & 61 & 50.0 \\
\hline 23 & 149.8 & 62 & 49.1 \\
\hline 24 & $(148.7)$ & 63 & 48.3 \\
\hline 25 & 148.5 & 64 & 47.4 \\
\hline 26 & 145.6 & 65 & 46.1 \\
\hline 27 & 144.5 & 66 & $(33.6)$ \\
\hline 28 & 143.5 & 67 & 32.1 \\
\hline 29 & $(141.2)$ & 68 & $(31.5)$ \\
\hline 30 & 138.7 & 69 & 29.9 \\
\hline 31 & 137.2 & 70 & 29.5 \\
\hline 32 & 136.8 & 71 & 28.4 \\
\hline 33 & 136.2 & 72 & $(27.2)$ \\
\hline 34 & 134.3 & 73 & $(24.6)$ \\
\hline 35 & 132.8 & 74 & 22.6 \\
\hline 36 & 130.8 & 75 & $(21.3)$ \\
\hline 37 & 129.7 & 76 & 19.1 \\
\hline 38 & 128.8 & 77 & $(13.5)$ \\
\hline 39 & 127.4 & 78 & (11.4) \\
\hline
\end{tabular}

${ }^{a_{T}}$ The signals attributed to the $\Phi_{\mathrm{A}}$ are given in parentheses. 
Table 2. ${ }^{13} \mathrm{C}$ NMR Chemical Shifts Assigned to BPhe $a$ and Its Monomers in Acetone, with Respective Theoretically Calculated Chemical Shift Differences between the Monomer and Protein-Bound BPhe $a$

\begin{tabular}{|c|c|c|c|c|c|c|}
\hline \multirow[b]{2}{*}{ IUPAC } & \multicolumn{6}{|c|}{${ }^{13} \mathrm{C}$ chemical shift (ppm) } \\
\hline & $\begin{array}{l}\text { observed shifts of } \\
\text { BPhe } a \text { in liquid } \\
\text { acetone }\end{array}$ & $\begin{array}{l}\text { observed shifts of BPhe } a \text { by } \\
\text { photo-CIDNP MAS NMR }\end{array}$ & $\begin{array}{l}\text { experimental } \Delta \sigma \\
\text { (solid-liquid) }\end{array}$ & $\begin{array}{l}\text { theoretically calculated } \\
\text { shifts of fully relaxed BPhe } a\end{array}$ & $\begin{array}{c}\text { theoretically calculated } \\
\text { shifts of constrained BPhe } a\end{array}$ & $\begin{array}{l}\text { theoretical } \Delta \sigma \\
(\text { const-relax) }\end{array}$ \\
\hline 1 & 139.7 & 141.2 & 1.5 & 140.7 & 140.7 & 0.0 \\
\hline 2 & 138.5 & 138.7 & 0.2 & 149.2 & 145.4 & -3.8 \\
\hline $2^{1}$ & 13.9 & 13.5 & -0.4 & 17.2 & 17.0 & -0.2 \\
\hline $3^{1}$ & 199.2 & 197.0 & -2.2 & 201.9 & 201.4 & -0.5 \\
\hline $3^{2}$ & 34.0 & 33.6 & -0.4 & 35.2 & 37.8 & 2.6 \\
\hline 4 & 138.1 & 137.2 & -0.9 & 142.3 & 142.6 & 0.3 \\
\hline 5 & 97.9 & 97.6 & -0.3 & 100.5 & 100.4 & -0.1 \\
\hline 6 & 172.4 & 172.9 & 0.5 & 173.5 & 171.3 & -2.2 \\
\hline $7^{1}$ & 23.7 & 24.6 & 0.9 & 25.7 & 26.5 & 0.8 \\
\hline 8 & 55.4 & 55.6 & 0.2 & 66.0 & 65.5 & -0.5 \\
\hline $8^{1}$ & 30.7 & 27.2 & -3.5 & 39.6 & 45.5 & 5.9 \\
\hline $8^{2}$ & 11.5 & 11.4 & -0.1 & 13.7 & 18.5 & 4.9 \\
\hline 9 & 164.3 & 168.2 & 3.9 & 173.1 & 175.0 & 1.9 \\
\hline 10 & 100.2 & 99.6 & -0.6 & 101.7 & 100.2 & -1.4 \\
\hline $12^{1}$ & 11.5 & 11.4 & -0.1 & 12.1 & 13.1 & 1.0 \\
\hline 13 & 129.2 & 126.9 & -2.3 & 138.6 & 137.6 & -1.0 \\
\hline $13^{1}$ & 189.3 & 188.6 & -0.7 & 196.3 & 193.5 & -2.8 \\
\hline $13^{2}$ & 65.5 & 65.8 & 0.3 & 76.3 & 75.1 & -1.3 \\
\hline $13^{3}$ & 170.2 & 169.3 & -0.9 & 179.4 & 178.5 & -0.9 \\
\hline 14 & 148.7 & 148.7 & 0.0 & 151.6 & 151.7 & 0.1 \\
\hline 15 & 110.3 & 107.5 & -2.8 & 119.3 & 117.8 & -1.5 \\
\hline 16 & 158.7 & 154.4 & -4.3 & 171.1 & 170.6 & -0.5 \\
\hline 17 & 51.4 & 51.7 & 0.3 & 64.4 & 62.7 & -1.7 \\
\hline $17^{1}$ & 31.3 & 31.5 & 0.2 & 35.3 & 33.3 & -2.0 \\
\hline 18 & 50.9 & 52.5 & 1.6 & 59.3 & 56.8 & -2.5 \\
\hline $18^{1}$ & 22.9 & 21.3 & -1.6 & 25.6 & 26.2 & 0.6 \\
\hline 19 & 171.7 & 170.7 & -1.0 & 174.4 & 172.1 & -2.3 \\
\hline 20 & 97.2 & 95.1 & -2.1 & 102.4 & 101.4 & -1.0 \\
\hline
\end{tabular}

carbons of $\Phi_{\mathrm{A}}$ in Table 2. The assignment is backed by theoretical calculations.

Trace A in Figure 4 represents the ${ }^{13} \mathrm{C}$ MAS NMR spectrum of u-ALA labeled RCs. The data are aligned with spectra collected from $\mathrm{RCs}$ obtained by feeding the $3-{ }^{13} \mathrm{C}_{1}$-ALA, $4-{ }^{13} C_{1}$-ALA, or $5-{ }^{13} C_{1}$-ALA labeled precursors in the growth medium for $R$. sphaeroides WT (Figure 4, traces B-D). From the spectra a peak list has been compiled consisting of 78 chemical shifts that are sequentially indexed (Table 1). Most of the signals from the Special Pair have been assigned straightforwardly on the basis of previous assignments from particular label patterns. $2,25,26,37,38,58$ These assignments are indicated with the dotted lines in Figure 4. The peaks indicated by solid lines are attributed to bacteriopheophytin, and the corresponding shifts are presented in italics in the Table 1 along with the index numbers, whereas Table 2 presents a self-consistent assignment of the signals that is based on the comparison with solution data, ${ }^{59} 2 \mathrm{D}$ data for RCs reconstituted with plant Pheo $a^{60}$ and the chemical shift calculations of the present paper.

In trace $A$ in Figure 5, the region between 200 and 180 ppm that is shown in Figure 4 is expanded and Lorentz fits and index numbers are added. Out of six signals, four signals are attributed to the carbonyls of the Special Pair cofactors, ${ }^{58}$ and are labeled in green. The other two, labeled in blue, are assigned to $\Phi_{\mathrm{A}}$. The response at $197.0 \mathrm{ppm}(\# 1)$ is attributed to $C 3^{1}$ of the $\Phi_{\mathrm{A}}$ and the signal at $188.6 \mathrm{ppm}(\# 5)$ is ascribed to $C 13^{1}$ of the $\Phi_{\mathrm{A}}$. The shifts are similar to the chemical shifts observed for the $\mathrm{C}^{1}$ (199.2 ppm) and $\mathrm{C}^{1} 3^{1}$ (189.3 ppm) response from monomeric BPhe $a$ in acetone solution ${ }^{59}$ and both signals align well with the downfield response from the $3-{ }^{13} \mathrm{C}_{1}$-ALA labeled RCs (Figure 4B). It appears that around 199.5 and $186.0 \mathrm{ppm}$ additional signals occur (indicated in orange) which do not originate from one of the three cofactors forming the primary radical pair (Figure 5). We assume that these signals originate from the $\mathrm{C}-3^{1}$ and $\mathrm{C}-13^{1}$ carbons of the accessory $\mathrm{BChl}$ and obtain their enhancement via spin diffusion in $\mathrm{u}^{13} \mathrm{C}_{5}$-ALA preparations through $\mathrm{C}-13^{1}$ and $\mathrm{C}-13^{2}$ of $\mathrm{P}_{\mathrm{L}}$ and $\mathrm{C}-2$ and $\mathrm{C}-2^{1}$ of $\mathrm{P}_{\mathrm{M}}$ but not in $3{ }^{13}-\mathrm{C}_{1}$-ALA labeled samples. The similar signal strengths for the various ${ }^{13} \mathrm{C}$ demonstrates the efficiency of the spin diffusion process in the solid matrix.

The region between 180 and $160 \mathrm{ppm}$ (Figure 5B) shows two sets of signals that reproduce well across the collection of labeled samples. The 8 strongest signals (\#12-19) originate from the Special Pair. ${ }^{2,38}$ In the downfield part of the region, 4 relatively weak peaks are discerned, $(\# 7-10)$ at 174.2, 172.9, 170.7 , and $169.3 \mathrm{ppm}$. These signals match very well with the $\mathrm{C} 17^{3}, \mathrm{C} 6, \mathrm{C} 19$, and $\mathrm{C} 13^{3}$ of the BPhe $a$ in solution and with the $2 \mathrm{D}$ correlation data collected from a sample reconstituted with uniformly labeled plant pheophytin $a .^{59,60}$ In addition the shift of 168.2 ppm for peak \#11 is in line with a previous photoCIDNP assignment for the C9 of the $\Phi_{\mathrm{A}}{ }^{2}{ }^{2}$

In the region between 160 and $140 \mathrm{ppm}$ (Figure 5C), most of the NMR response is due to aromatic carbons of the Special Pair cofactors $\mathrm{P}_{\mathrm{L}}$ and $\mathrm{P}_{\mathrm{M}}{ }^{2,38}$ Only the signals with index 20, 24, 


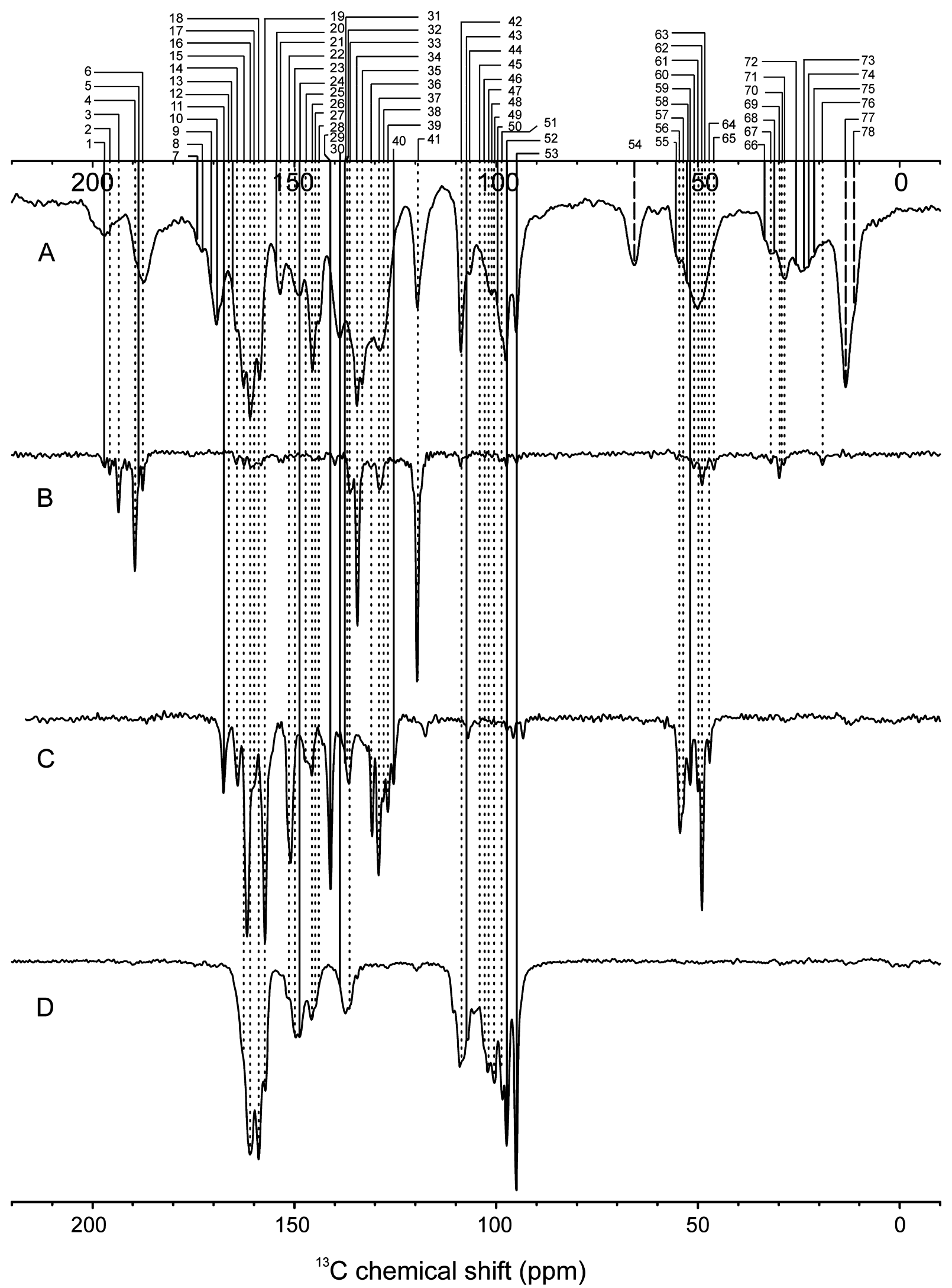

Figure 4. Set of one-dimensional ${ }^{13} \mathrm{C}$ photo-CIDNP MAS NMR spectra collected from (A) u-ALA, (B) 3-ALA, (C) 4-ALA, and (D) 5-ALA labeled RCs of $R$ sphaeroides WT under continuous light in a magnetic field of $4.7 \mathrm{~T}$ and at a temperature of $223 \mathrm{~K}$. The spinning frequency was set to $8 \mathrm{kHz}$. The dashed lines indicate the responses from $\mathrm{P}_{\mathrm{L}}$ and $\mathrm{P}_{\mathrm{M}}$ using the assignments obtained in previous work, whereas the signals from the $\Phi_{\mathrm{A}}$ are designated by solid lines. When signals from the $\mathrm{P}_{\mathrm{L}}, \mathrm{P}_{\mathrm{M}}$, and the $\Phi_{\mathrm{A}}$ coincide, their position is indicated with dashed lines. 

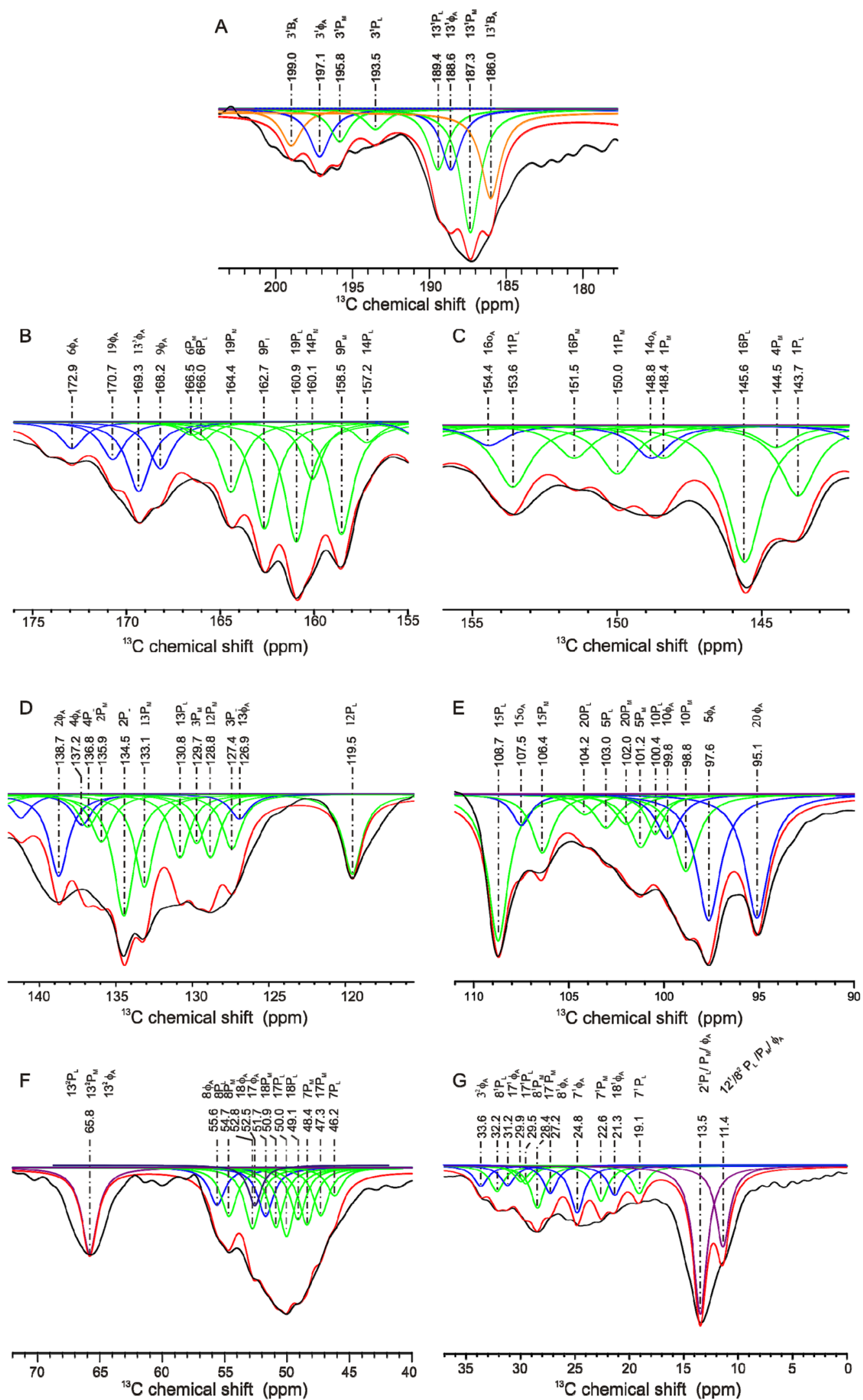

Figure 5. One-dimensional ${ }^{13} \mathrm{C}$ photo-CIDNP MAS NMR spectrum of u-ALA labeled RCs of $R$. sphaeroides WT under continuous light collected at a magnetic field of $4.7 \mathrm{~T}$ and a temperature of $223 \mathrm{~K}$ with spinning frequency of $8 \mathrm{kHz}$ (black). The spectrum has been fitted with Lorentz function of same line width. The signals of carbons from $\mathrm{P}_{\mathrm{L}}$ and $\mathrm{P}_{\mathrm{M}}$ which had been established in previous work are shown in green. Signals from $\Phi_{A}$, discussed in the present work, are shown in blue. The orange colored signals could be from the accessory $\mathrm{BChl}\left(\mathrm{B}_{\mathrm{A}}\right)$. The sum of all fitted peaks in the spectrum is given in red color. 
A

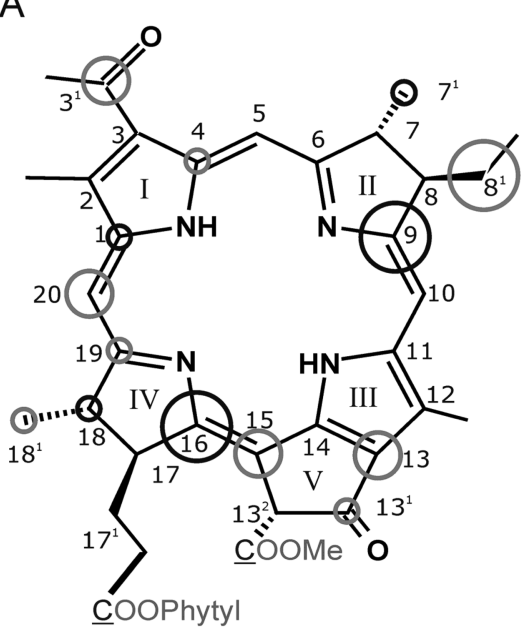

B

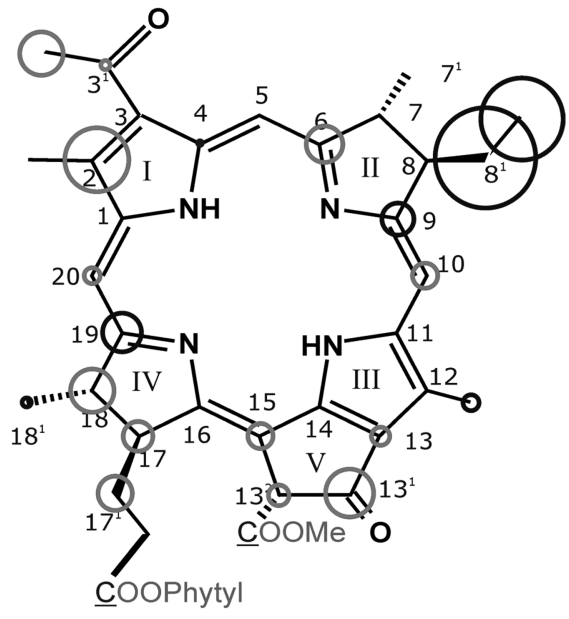

$\mathbf{O}=+1 \mathrm{ppm} O=-1 \mathrm{ppm}$

Figure 6. Relative shift differences of bacteriopheophytin $\left(\Phi_{\mathrm{A}}\right)$ in the electronic ground state derived (A) experimentally from the chemical shift differences between monomeric BPhe $a$ in solution in acetone and $\Phi_{\mathrm{A}}$ cofactor in the RC and (B). Theoretically calculated chemical shift differences between the fully relaxed structure and a constrained partially optimized structure of BPhe $a$ from the X-ray structure from $1 \mathrm{M} 3 \mathrm{X}$.

and 29 , are attributed to $\Phi_{\mathrm{A}}$. In the region between 140 and 119 ppm (\#30-41), all signals that originate from the Special Pair and bacteriopheophytin have been assigned before. ${ }^{2}$ The relatively strong response in this region is in line with the assignments to carbons of the aromatic ring, which is the source of buildup of nuclear spin polarization. ${ }^{24}$

For the region between 110 and $90 \mathrm{ppm}($ Figure 5D) four signals can be attributed to the $\Phi_{\mathrm{A}}$. Three of these signals (\#43, 52, and 53) have been identified earlier. ${ }^{38}$ The peak at $99.6 \mathrm{ppm}(\# 50)$ is ascribed to the $\mathrm{C} 10\left(\Phi_{\mathrm{A}}\right)$. The relatively intense response from the $\mathrm{C} 5$ at $97.6 \mathrm{ppm}$ and the $\mathrm{C} 20$ at $95.1 \mathrm{ppm}$ confirms that these $\Phi_{\mathrm{A}}$ signals are from carbons in the aromatic ring.

In the aliphatic region of the spectrum (Figure $5 \mathrm{E}$ ), the signals at $55.6(\# 55)$ and 52.5 (\#58) ppm are attributed to the C8 and the C18 of the $\Phi_{A}$, while the other signals were already assigned from photo-CIDNP MAS NMR data collected from $3-{ }^{13} \mathrm{C}_{1}$-ALA and $4-{ }^{13} \mathrm{C}_{1}$-ALA labeled RCs. ${ }^{2}$ The distinct peak at $65.8 \mathrm{ppm}$ (Figure $5 \mathrm{~F}, \# 54$ ) is assigned to carbon $\mathrm{C}_{13}{ }^{2}$ from all cofactors by analogy with data for the $\mathrm{BChl}$ and $\mathrm{BPhe}$ monomers in solution. ${ }^{39}$ In the region between 40 and $0 \mathrm{ppm}$ (Figure 5G), most of the signals, with indices between 66 and 78, are from the Special Pair. ${ }^{58}$ The remaining peaks at 33.6, $31.5,27.2,24.6$, and $21.3 \mathrm{ppm}$ are tentatively assigned to the bacteriopheophytin by comparing with the solution data of BPhe. ${ }^{59}$ Two distinct signals at 13.5 and 11.4 ppm (\#77 and 78) indicated by dashed lines, represent the collective responses from the peripheral carbons $\mathrm{C} 2^{1}$ and $\mathrm{C} 12^{1}$ or $\mathrm{C} 8^{2}$ of all cofactors.

Although some assignments are tentative, a consistent chemical shift pattern is presented. In particular for the carbon signals that are well resolved, the assignments are conclusive.

Tuning of $\boldsymbol{\Phi}_{\mathrm{A}}$ in the Protein Matrix. During electron transfer, the bacteriopheophytin in the active branch forms a radical pair state with the Special Pair. The specific purpose of the present study is to provide an experimental underpinning of the role of the $\Phi_{\mathrm{A}}$ in the ground state activation process, and use photo-CIDNP solid state NMR to probe the perturbation of the $\Phi_{\mathrm{A}}$ primary acceptor, relative to monomeric BPhe in solution, by measuring the chemical shifts for ${ }^{13} \mathrm{C}$ nuclei in the macrocycle. The NMR resonances are very sensitive to changes in the electronic and spatial structure and provide a microscopic view on how the protein matrix affects the cofactors for possible tuning of the site energies and accompanying vibrational activation. Figure 6A shows the experimental data, comparing chemical shifts for the BPhe $a$ in solution and in the protein matrix. Figure $6 \mathrm{~B}$ presents calculated chemical shifts for a fully relaxed state and the constrained geometry of the protein. In both cases, the changes are minor and within the accuracy limit of the calculations. Compared with the large shift differences between the two halves of the special pair, which are up to $11 \mathrm{ppm},{ }^{37}$ the overall changes for BPhe $a\left(\Phi_{\mathrm{A}}\right)$ compared to the monomeric species in solution are very small. This includes the signal from the soft joints of $\mathrm{C} 5$ and $\mathrm{C} 10$, which indicates a planar ring conformation. The largest changes are observed for sterically constrained atoms as $\mathrm{C}^{1}, \mathrm{C} 13, \mathrm{C} 15$, and $\mathrm{C} 20$ $(\sim 2.0 \mathrm{ppm})$ and for the $\mathrm{C}^{1}, \mathrm{C} 9$, and $\mathrm{C} 16$ atoms $(\sim 3.5 \mathrm{ppm})$ demonstrating a very limited matrix effect by protonic or electronic influences. Hence, our data clearly demonstrate that BPhe $a$ in the bacterial RC of R. sphaeroides is electronically close to its state in solution in acetone and its ground-state structure is not significantly modified by interactions, either with the protein or with other cofactors. This conclusion is well in line with electrochemical investigations. ${ }^{61-63}$

The similarity between the NMR shifts for the $\Phi_{\mathrm{A}}$ and monomeric BPhe $a$ contrasts with the differences in chemical shifts for the two BChl $a$ cofactors in the Special Pair $\left(\mathrm{P}_{\mathrm{L}}\right.$ and $\left.\mathrm{P}_{\mathrm{M}}\right)$. $^{58}$ Since the $\Phi_{\mathrm{A}}$ is involved in the cascade of charge separation events in the RC and symmetry breaking is related to structural distortions in the ground state, ${ }^{2,40,64,65}$ the data contribute to converging evidence that the primary source of the symmetry breaking is in the deformation of $\mathrm{P}$, whereas the extent of protein induced deformation of the BPhe $a$ molecule appears to be much less. Apparently there is very little tuning of the BPhe of the active branch by its surroundings and it represents an electron sink due to its redox potential that is different from P. A similar conclusion has been made for the next cofactor in the electron conversion chain, the quinone acceptor $\mathrm{Q}_{A}$ in $\mathrm{RCs}$, which is thought to remain in the same orientation upon illumination of the RC with light. ${ }^{66}$ 


\section{CONCLUSION}

The photo-CIDNP MAS NMR analysis of the pheophytin of the active branch, $\Phi_{\mathrm{A}}$, demonstrates that this cofactor is hardly affected by the protein environment. The origin of the functional symmetry break in RCs of $R$. sphaeroides is therefore not the acceptor side but the donor side.

\section{AUTHOR INFORMATION}

\section{Notes}

The authors declare no competing financial interest.

\section{ACKNOWLEDGMENTS}

The help of F. Lefeber and K. Erkelens is gratefully acknowledged. The authors thank Dr. B. Bode and Dr. S. Prakash for exciting discussions. Generous support of the Cyttron network is acknowledged. The use of supercomputer facilities was sponsored by The Netherlands National Computing Facilities Foundation (NCF).

\section{ABBREVIATIONS}

ALA, $\delta$-aminolevulinic acid; BPhe $a$, bacteriopheophytin $a$; BChl, bacteriochlorophyll $a$; ET, electron transfer; MAS, magicangle spinning; $\mathrm{P}$, special pair; photo-CIDNP MAS NMR, photochemically induced dynamic nuclear polarization; $R$. sphaeroides, Rhodobacter sphaeroides; RCs, reaction centers; WT, wild type

\section{REFERENCES}

(1) Alia, A.; Wawrzyniak, P. K.; Janssen, G. J.; Buda, F.; Matysik, J.; de Groot, H. J. M. Differential Charge Polarization of Axial Histidines in Bacterial Reaction Centers Balances the Asymmetry of the Special Pair. J. Am. Chem. Soc. 2009, 131, 9626-9627.

(2) Daviso, E.; Prakash, S.; Alia, A.; Gast, P.; Neugebauer, J.; Jeschke, G.; Matysik, J. The Electronic Structure of the Primary Electron Donor of Reaction Centers of Purple Bacteria at Atomic Resolution as Observed by Photo-CIDNP ${ }^{13} \mathrm{C}$ NMR. Proc. Natl. Acad. Sci. U.S.A. 2009, 106, 22281-22286.

(3) Raszewski, G.; Saenger, W.; Renger, T. Theory of Optical Spectra of Photosystem Ii Reaction Centers: Location of the Triplet State and the Identity of the Primary Electron Donor. Biophys. J. 2005, 88, 986998.

(4) Eisenmayer, T. J.; de Groot, H. J. M.; van de Wetering, E.; Neugebauer, J.; Buda, F. Mechanism and Reaction Coordinate of Directional Charge Separation in Bacterial Reaction Centers. J. Phys. Chem. Lett. 2012, 3, 694-697.

(5) Pandit, A.; Wawrzyniak, P. K.; van Gammeren, A. J.; Buda, F.; Ganapathy, S.; de Groot, H. J. M. Nuclear Magnetic Resonance Secondary Shifts of a Light-Harvesting 2 Complex Reveal Local Backbone Perturbations Induced by Its Higher-Order Interactions. Biochemistry 2010, 49, 478-486.

(6) Pandit, A.; de Groot, H. J. M. Solid-State NMR Applied to Photosynthetic Light-Harvesting Complexes. Photosynth. Res. 2012, $111,219-226$.

(7) Photosynthetic Protein Complexes; Fromme, P., Ed.; WileyBlackwell: Weinheim, Germany, 2008.

(8) Yeates, T. O.; Komiya, H.; Chirino, A.; Rees, D. C.; Allen, J. P.; Feher, G. Structure of the Reaction Center from Rhodobacter sphaeroides R-26 and 2.4.1-Protein-Cofactor (Bacteriochlorophyll, Bacteriopheophytin, and Carotenoid) Interactions 0.4. Proc. Natl. Acad. Sci. U.S.A. 1988, 85, 7993-7997.

(9) Ermler, U.; Fritzsch, G.; Buchanan, S. K.; Michel, H. Structure of the Photosynthetic Reaction-Center from Rhodobacter sphaeroides at 2.65-Ångström Resolution Cofactors and Protein-Cofactor Interactions. Structure 1994, 2, 925-936.
(10) Camara-Artigas, A.; Brune, D.; Allen, J. P. Interactions between Lipids and Bacterial Reaction Centers Determined by Protein Crystallography. Proc. Natl. Acad. Sci. U.S.A. 2002, 99, 11055-11060.

(11) Novoderezhkin, V. I.; Yakovlev, A. G.; van Grondelle, R.; Shuvalov, V. A. Coherent Nuclear and Electronic Dynamics in Primary Charge Separation in Photosynthetic Reaction Centers: A Redfield Theory Approach. J. Phys. Chem. B 2004, 108, 7445-7457.

(12) Shkuropatov, A. Y.; Shuvalov, V. A. Electron Transfer in Pheophytin a-Modified Reaction Centers from Rhodobacter sphaeroides R-26. FEBS Lett. 1993, 322, 168-172.

(13) Eisenmayer, T. J.; de Groot, H. J. M.; van de Wetering, E.; Neugebauer, J.; Buda, F. Mechanism and Reaction Coordinate of Directional Charge Separation in Bacterial Reaction Centers. J. Phys. Chem. Lett. 2012, 3, 694-697.

(14) Lubitz, W.; Abresch, E. C.; Debus, R. J.; Isaacson, R. A.; Okamura, M. Y.; Feher, G. Electron Nuclear Double Resonance of Semiquinones in Reaction Centers of Rhodopseudomonas sphaeroides. Biochim. Biophys. Acta, Bioenerg. 1985, 808, 464-469.

(15) Lubitz, W.; Feher, G. The Primary and Secondary Accepters in Bacterial Photosynthesis Iii. Characterization of the Quinone Radicals $\mathrm{Q}^{-\cdot}$ And $\mathrm{Q}_{\mathrm{b}}^{-\cdot}$ By EPR and Endor. Appl. Magn. Reson. 1999, 17, 1-48.

(16) Feher, G.; Okamura, M. Y.; McElroy, J. D. Identification of an Electron Acceptor in Reaction Centers of Rhodopseudomonas spheroides by EPR Spectroscopy. Biochim. Biophys. Acta, Bioenerg. 1972, 267, 222-226.

(17) Holzwarth, A. R.; Müller, M. G. Energetics and Kinetics of Radical Pairs in Reaction Centers from Rhodobacter sphaeroides. A Femtosecond Transient Absorption Study. Biochemistry 1996, 35, $11820-11831$.

(18) Schmidt, S.; Arlt, T.; Hamm, P.; Huber, H.; Nägele, T.; Wachtveitl, J.; Meyer, M.; Scheer, H.; Zinth, W. Energetics of the Primary Electron Transfer Reaction Revealed by Ultrafast Spectroscopy on Modified Bacterial Reaction Centers. Chem. Phys. Lett. 1994, 223, 116-120.

(19) Franken, E. M.; Shkuropatov, A. Y.; Francke, C.; Neerken, S.; Gast, P.; Shuvalov, V. A.; Hoff, A. J.; Aartsma, T. J. Reaction Centers of Rhodobacter sphaeroides R-26 with Selective Replacement of Bacteriopheophytin by Pheophytin A: I. Characterisation of SteadyState Absorbance and Circular Dichroism, and of the $\mathrm{P}^{+} \mathrm{Q}^{-}$State. Biochim. Biophys. Acta, Bioenerg. 1997, 1319, 242-250.

(20) Moore, L. J.; Zhou, H.; Boxer, S. G. Excited-State Electronic Asymmetry of the Special Pair in Photosynthetic Reaction Center Mutants. Absorpt. Stark Spectrosc. 1999, 38, 11949-11960.

(21) Zucchelli, G.; Brogioli, D.; Casazza, A. P.; Garlaschi, F. M.; Jennings, R. C. Chlorophyll Ring Deformation Modulates Qy Electronic Energy in Chlorophyll-Protein Complexes and Generates Spectral Forms. Biophys. J. 2007, 93, 2240-2254.

(22) Zysmilich, M. G.; McDermott, A. Photochemically Induced Dynamic Nuclear-Polarization in the Solid-State ${ }^{15} \mathrm{n}$ Spectra of Reaction Centers from Photosynthetic Bacteria Rhodobacter sphaeroides R-26. J. Am. Chem. Soc. 1994, 116, 8362-8363.

(23) Jeschke, G.; Matysik, J. A Reassessment of the Origin of Photochemically Induced Dynamic Nuclear Polarization Effects in Solids. Chem. Phys. 2003, 294, 239-255.

(24) Daviso, E.; Alia, A.; Prakash, S.; Diller, A.; Gast, P.; Lugtenburg, J.; Matysik, J.; Jeschke, G. Electron-Nuclear Spin Dynamics in a Bacterial Photosynthetic Reaction Center. J. Phys. Chem. C 2009, 113, 10269-10278.

(25) Prakash, S.; Alia; Gast, P.; de Groot, H. J. M.; Jeschke, G.; Matysik, J. Magnetic Field Dependence of Photo-CIDNP MAS NMR on Photosynthetic Reaction Centers of Rhodobacter sphaeroides WT. J. Am. Chem. Soc. 2005, 127, 14290-14298.

(26) Prakash, S.; Alia; Gast, P.; de Groot, H. J. M.; Matysik, J.; Jeschke, G. Photo-CIDNP MAS NMR in Intact Cells of Rhodobacter sphaeroides R-26: Molecular and Atomic Resolution at Nanomolar Concentration. J. Am. Chem. Soc. 2006, 128, 12794-12799.

(27) Roy, E.; Rohmer, T.; Gast, P.; Jeschke, G.; Alia, A.; Matysik, J. Characterization of the Primary Radical Pair in Reaction Centers of 
Heliobacillus mobilis by ${ }^{13} \mathrm{C}$ Photo-CIDNP MAS NMR. Biochemistry 2008, 47, 4629-4635.

(28) Thamarath, S. S.; Bode, B. E.; Prakash, S.; Sai Sankar Gupta, K. B.; Alia, A.; Jeschke, G.; Matysik, J. C. r. Electron Spin Density Distribution in the Special Pair Triplet of Rhodobacter sphaeroides R26 Revealed by Magnetic Field Dependence of the Solid-State PhotoCidnp Effect. J. Am. Chem. Soc. 2012, 134, 5921-5930.

(29) Diller, A.; Alia, A.; Gast, P.; Jeschke, G.; Matysik, J. ${ }^{13}$ C PhotoCIDNP MAS NMR on the LH1-RC Complex of Rhodopseudomonas Acidophila. Photosynthesis. Energy Sun 2008, 55-58.

(30) Roy, E.; Diller, A.; Alia; Gast, P.; van Gorkom, H. J.; de Groot, H. J. M.; Jeschke, G.; Matysik, J. Magnetic Field Dependence of ${ }^{13} \mathrm{C}$ Photo-CIDNP MAS NMR in Plant Photosystems I and II. Appl. Magn. Reson. 2007, 31, 193-204.

(31) Matysik, J.; Alia; Gast, P.; van Gorkom, H. J.; Hoff, A. J.; de Groot, H. J. M. Photochemically Induced Nuclear Spin Polarization in Reaction Centers of Photosystem II Observed by ${ }^{13} \mathrm{C}$-Solid-State NMR Reveals a Strongly Asymmetric Electronic Structure of the P680. + Primary Donor Chlorophyll. Proc. Natl. Acad. Sci. U.S.A. 2000, 97, 9865-9870.

(32) Alia, A.; Roy, E.; Gast, P.; van Gorkom, H. J.; de Groot, H. J. M.; Jeschke, G.; Matysik, J. Photochemically Induced Dynamic Nuclear Polarization in Photosystem I of Plants Observed by ${ }^{13} \mathrm{C}$ Magic-Angle Spinning NMR. J. Am. Chem. Soc. 2004, 126, 12819-12826.

(33) Diller, A.; Alia, A.; Roy, E.; Gast, P.; de Groot, H.; van Gorkom, H.; Jeschke, G.; Matysik, J. The Origin of the High Redox Force of Photosystem II: A Photo-Cidnp MAS NMR Analysis 2007, 91, PS246.

(34) Matysik, J.; Diller, A.; Roy, E.; Alia, A. The Solid-State PhotoCidnp Effect. Photosynth. Res. 2009, 102, 427-435.

(35) Janssen, G. J.; Daviso, E.; van Son, M.; de Groot, H. J. M.; Alia, A.; Matysik, J. Observation of the Solid-State Photo-Cidnp Effect in Entire Cells of Cyanobacteria Synechocystis. Photosynth. Res. 2010, 104, 275-282.

(36) Thamarath Surendran, S.; Heberle, J.; Hore, P. J.; Kottke, T.; Matysik, J. Solid-State Photo-CIDNP Effect Observed in Phototropin Lov1-C57s by ${ }^{13} \mathrm{C}$ Magic-Angle Spinning NMR Spectroscopy. J. Am. Chem. Soc. 2010, 132, 15542-15543.

(37) Schulten, E. A. M.; Matysik, J.; Alia; Kiihne, S.; Raap, J.; Lugtenburg, J.; Gast, P.; Hoff, A. J.; de Groot, H. J. M. ${ }^{13}$ C Mas Nmr and Photo-CIDNP Reveal a Pronounced Asymmetry in the Electronic Ground State of the Special Pair of Rhodobacter sphaeroides Reaction Centers. Biochemistry 2002, 41, 8708-8717.

(38) Prakash, S.; Alia, A.; Gast, P.; de Groot, H. J. M.; Jeschke, G.; Matysik, J. ${ }^{13} \mathrm{C}$ Chemical Shift Map of the Active Cofactors in Photosynthetic Reaction Centers of Rhodobacter sphaeroides Revealed by Photo-CIDNP MAS NMR. Biochemistry 2007, 46, 8953-8960.

(39) Wawrzyniak, P. K.; Beerepoot, M.; de Groot, H. J. M.; Buda, F. Acetyl Group Orientation Modulates the Electronic Ground-State Asymmetry of the Special Pair in Purple Bacterial Reaction Centers. Phys. Chem. Chem. Phys. 2011, 13, 10270-10279.

(40) Yamasaki, H.; Takano, Y.; Nakamura, H. Theoretical Investigation of the Electronic Asymmetry of the Special Pair Cation Radical in the Photosynthetic Type-II Reaction Center. J. Phys. Chem. B 2008, 112, 13923-13933.

(41) Wawrzyniak, P. K. Ab Initio Modeling of Primary Processes in Photosynthesis: Protein Induced Activation of Bacteriochlorophylls for Efficient Light Harvesting and Charge Separation; Leiden University, 2011.

(42) Franken, E. M.; Shkuropatov, A. Y.; Francke, C.; Neerken, S.; Gast, P.; Shuvalov, V. A.; Hoff, A. J.; Aartsma, T. J. Reaction Centers of Rhodobacter sphaeroides R-26 with Selective Replacement of Bacteriopheophytin $a$ by Pheophytin $a$ : II. Temperature Dependence of the Quantum Yield of $\mathrm{P}^{+} \mathrm{Q}^{-}$and ${ }^{3} \mathrm{P}$ Formation. Biochim. Biophys. Acta, Bioenerg. 1997, 1321, 1-9.

(43) Jordan, P. M. In Bio Synthesis of Tetrapyrroles; Elsevier: Amsterdam, 1991.

(44) Matysik, J.; Schulten, E.; Alia; Gast, P.; Raap, J.; Lugtenburg, J.; Hoff, A. J.; de Groot, H. J. M. Photo-CIDNP ${ }^{13} \mathrm{C}$ Magic Angle Spinning Nmr on Bacterial Reaction Centres: Exploring the Electronic
Structure of the Special Pair and Its Surroundings. Biol. Chem. 2001, $382,1271-1276$.

(45) Shochat, S.; Arlt, T.; Francke, C.; Gast, P.; Vannoort, P. I.; Otte, S. C. M.; Schelvis, H. P. M.; Schmidt, S.; Vijgenboom, E.; Vrieze, J.; et al. Spectroscopic Characterization of Reaction Centers of the (M)Y210W Mutant of the Photosynthetic Bacterium Rhodobacter sphaeroides. Photosynth. Res. 1994, 40, 55-66.

(46) Okamura, M. Y.; Isaacson, R. A.; Feher, G. Primary Acceptor in Bacterial Photosynthesis - Obligatory Role of Ubiquinone in Photoactive Reaction Centers of Rhodopseudomonas-Spheroides. Proc. Natl. Acad. Sci. U.S.A. 1975, 72, 3491-3495.

(47) Fischer, M. R.; Degroot, H. J. M.; Raap, J.; Winkel, C.; Hoff, A. J.; Lugtenburg, J. ${ }^{13} \mathrm{C}$ Magic Angle Spinning NMR-Study of the LightInduced and Temperature-Dependent Changes in Rhodobacter sphaeroides R-26 Reaction Centers Enriched in $4{ }^{\prime}-{ }^{13} \mathrm{C}$ Tyrosine. Biochemistry 1992, 31, 11038-11049.

(48) Bennett, A. E.; Rienstra, C. M.; Auger, M.; Lakshmi, K. V.; Griffin, R. G. Heteronuclear Decoupling in Rotating Solids. J. Chem. Phys. 1995, 103, 6951-6958.

(49) Fonseca Guerra, C.; Snijders, J. G.; te Velde, G.; Baerends, E. J. Towards an Order-N DFT Method. Theor. Chem. Acc. 1998, 99, 391403-403.

(50) te Velde, G.; Bickelhaupt, F. M.; Baerends, E. J.; Fonseca Guerra, C.; van Gisbergen, S. J. A.; Snijders, J. G.; Ziegler, T. Chemistry with ADF. J. Comput. Chem. 2001, 22, 931-967.

(51) ADF2009.01. S C M, Theoretical Chemistry; Vrije Universiteit: Amsterdam, The Netherlands, 2009; http://Www.Scm.Com..

(52) Becke, A. D. Density-Functional Exchange-Energy Approximation with Correct Asymptotic-Behavior. Phys. Rev. A 1988, 38, $3098-3100$

(53) Lee, C. T.; Yang, W. T.; Parr, R. G. Development of the ColleSalvetti Correlation-Energy Formula into a Functional of the ElectronDensity. Phys. Rev. B 1988, 37, 785-789.

(54) Daviso, E.; Jeschke, G.; Matysik, J. Photochemically Induced Dynamic Nuclear Polarization (Photo-CIDNP) Magic-Angle Spinning NMR. In Biophysical Techniques in Photosynthesis II; Aartsma, T., Matysik, J., Eds.; Springer: Dordrecht, 2008; pp 385-399.

(55) Grommek, A.; Meier, B. H.; Ernst, M. Distance Information from Proton-Driven Spin Diffusion under Mas. Chem. Phys. Lett. 2006, 427, 404-409.

(56) Castellani, F.; van Rossum, B.; Diehl, A.; Schubert, M.; Rehbein, K.; Oschkinat, H. Structure of a Protein Determined by Solid-State Magic-Angle-Spinning Nmr Spectroscopy. Nature 2002, 420, 98-102.

(57) Bayro, M. J.; Huber, M.; Ramachandran, R.; Davenport, T. C.; Meier, B. H.; Ernst, M.; Griffin, R. G. Dipolar Truncation in MagicAngle Spinning NMR Recoupling Experiments. J. Chem. Phys. 2009, $130,114506-8$

(58) Sai Sankar Gupta, K. B. Spin-Torch Experiment on Reaction Centers of Rhodobacter sphaeroides; Leiden University, 2011.

(59) Egorova-Zachernyuk, T.; Rossum, B. v.; Erkelens, C.; de Groot, $\mathrm{H}$. Characterisation of Uniformly ${ }^{13} \mathrm{C},{ }^{15} \mathrm{~N}$ Labelled Bacteriochlorophyll $a$ and Bacteriopheophytin $a$ in Solution and in Solid State: Complete Assignment of the ${ }^{13} \mathrm{C},{ }^{1} \mathrm{H}$, and ${ }^{15} \mathrm{~N}$ Chemical Shifts. Magn. Reson. Chem. 2008, 46, 1074-1083.

(60) Egorova-Zachernyuk, T. A.; van Rossum, B.; Boender, G.-J.; Franken, E.; Ashurst, J.; Raap, J.; Gast, P.; Hoff, A. J.; Oschkinat, H.; de Groot, H. J. M. Characterization of Pheophytinground States in Rhodobacter sphaeroides R26 Photosynthetic Reaction Centers from Multispin Pheophytin Enrichment and 2-D ${ }^{13} \mathrm{C}$ MAS NMR Dipolar Correlation Spectroscopy. Biochemistry 1997, 36, 7513-7519.

(61) Cotton, T. M.; Van Duyne, R. P. An Electrochemical Investigation of the Redox Properties of Bacteriochlorophyll and Bacteriopheophytin in Aprotic Solvents. J. Am. Chem. Soc. 1979, 101, 7605-7612.

(62) Noy, D.; Moser, C. C.; Dutton, P. L. Design and Engineering of Photosynthetic Light-Harvesting and Electron Transfer Using Length, Time, and Energy Scales. Biochim. Biophys. Acta, Bioenerg. 2006, 1757, 90-105. 
(63) Woodbury, N. W. T.; Parson, W. W. Nanosecond Fluorescence from Isolated Photosynthetic Reaction Centers of Rhodopseudomonas sphaeroides. Biochim. Biophys. Acta, Bioenerg. 1984, 767, 345-361.

(64) Wawrzyniak, P. K.; Beerepoot, M.; de Groot, H. J. M.; Buda, F. Origin of Asymmetry in the Special Pair of Bacterial Reaction Center. Phys. Chem. Chem. Phys. 2011.

(65) Pandit, A.; Buda, F.; van Gammeren, A. J.; Ganapathy, S.; de Groot, H. J. M. Selective Chemical Shift Assignment of Bacteriochlorophyll $a$ in Uniformly $\left[{ }^{13} \mathrm{C},{ }^{15} \mathrm{~N}\right]$-Labeled Light-Harvesting 1 Complexes by Solid-State NMR in Ultrahigh Magnetic Field. J. Phys. Chem. B. 2010, 114, 6207-6215.

(66) Flores, M.; Savitsky, A.; Paddock, M. L.; Abresch, E. C.; Dubinskii, A. A.; Okamura, M. Y.; Lubitz, W.; Moebius, K. ElectronNuclear and Electron-Electron Double Resonance Spectroscopies Show That the Primary Quinone Acceptor Q(a) in Reaction Centers from Photosynthetic Bacteria Rhodobacter sphaeroides Remains in the Same Orientation Upon Light-Induced Reduction. J. Phys. Chem. B 2010, 114, 16894-16901. 